\title{
Evaluation of stress and anxiety caused by the coronavirus disease 2019 (COVID-19) pandemic in pediatric radiology
}

\author{
Rama S. Ayyala ${ }^{1,2}$ (D) $\cdot$ Grayson Baird $^{3} \cdot$ David A. Bloom $^{4} \cdot$ Janice D. McDaniel $^{5} \cdot$ Brooke Lampl $^{6}$ \\ Received: 2 November 2020 / Revised: 1 March 2021 / Accepted: 20 April 2021 / Published online: 14 May 2021 \\ (C) The Author(s), under exclusive licence to Springer-Verlag GmbH Germany, part of Springer Nature 2021
}

\begin{abstract}
Background Work-related stress and burnout were documented to be high among pediatric radiologists prior to the coronavirus disease 2019 (COVID-19) pandemic. New challenges arose from the COVID-19 pandemic, potentially introducing new stressors and anxieties.

Objective To evaluate potential sources of stress and anxiety for pediatric radiology faculty during the early phase of the COVID19 pandemic.

Materials and methods We conducted a survey of attending physician members of the Society for Pediatric Radiology in North America from April 27, 2020, to May 22, 2020. The response rate was 21\% (251/1,206). Survey questions included demographic information and questions regarding working remotely, personal protective equipment, redeployment, personal wellness, wellness resources and financial concerns. A psychometrician reviewed the questions to ensure minimal risk of misinterpretation. Results Median age of respondents was 48 years (range 33-70 years) with median number of years in practice of 14 (range 145 years). Fifty-three percent of respondents were women and $46 \%$ were men. Because of an increase in remote work, $69 \%$ of respondents endorsed feeling more isolated from a lack of regular interaction with colleagues. Fifty-three percent of respondents indicated that it is challenging to work remotely while overseeing home schooling for children. In comparison to men, women reported overall higher work-related stress and anxiety $(P=0.02)$, higher feelings of guilt from radiology staff (i.e. technologists and nurses) being more exposed to COVID-19 $(P=0.02)$ and higher levels of stress providing for dependents $(P=0.04)$. Most respondents thought that departmental leadership was effective and respondents were not concerned about meeting financial obligations or job loss.

Conclusion The early phase of the COVID-19 pandemic caused additional stress and anxiety for pediatric radiology faculty and disproportionally affected women. Given the continuously evolving state of the COVID-19 pandemic, these results could aid in planning and implementation of future strategies to combat burnout in radiology. Specific attention should be directed to different stressors experienced by female versus male radiologists, especially in regard to dependent care.
\end{abstract}

Keywords Anxiety $\cdot$ Burnout $\cdot$ Coronavirus $\cdot$ COVID-19 $\cdot$ Pediatric radiology $\cdot$ Radiologists $\cdot$ Stress $\cdot$ Women

\section{Introduction}

In early 2020 , there was rapid spread of severe acute respiratory syndrome coronavirus 2 (SARS-CoV-2), the cause of the

Rama S. Ayyala

rama.ayyala@cchmc.org

1 Department of Radiology,

Cincinnati Children's Hospital Medical Center,

3333 Burnett Ave, Cincinnati, OH 45229, USA

2 Department of Radiology,

University of Cincinnati College of Medicine,

Cincinnati, OH, USA coronavirus disease 2019 (COVID-19), throughout the world, leading to a large number of illnesses and deaths and the subsequent declaration of a global pandemic. In March 2020, the United States experienced rapidly rising

3 Department of Diagnostic Imaging, Rhode Island Hospital — Hasbro Children's Hospital, Warren Alpert Medical School of Brown University, Providence, RI, USA

4 Section of Pediatric Radiology, C. S. Mott Children's Hospital, Department of Radiology, Michigan Medicine,

University of Michigan Medical School, Ann Arbor, MI, USA

5 Department of Radiology, Akron Children's Hospital, Akron, $\mathrm{OH}, \mathrm{USA}$

6 Department of Radiology, Cleveland Clinic, Cleveland, OH, USA 
levels of infection and death, prompting the implementation of state and federally mandated social distancing guidelines [1]. This imposed severe restrictions on daily activities for many individuals, impacting daily work routines, canceling inperson schooling for children, and interrupting availability of elder and childcare.

During this time of mandated social distancing, given the widespread uncertainty regarding the virus and its implications, departments and institutions had little to no guidance on how to navigate the imposed changes. Since then, various institutional experiences have been shared; however, the situation remains fluid $[2,3]$. During the time of mandated social distancing, use of health care resources was limited to vital usage for emergent and inpatient indications. Radiology departments experienced significantly decreased examination volumes because of the cancellation or postponement of non-urgent outpatient imaging studies and procedures. Practice changes included ensuring safe work environments within the department to best protect staff while providing good patient care. One key factor in ensuring safety was securing adequate quantities of personal protective equipment (PPE) [4]. Another factor was creating and implementing remote workspaces for radiologists to further enhance the practice of social distancing.

With these changes, new stresses and anxieties arose, some of which differed from previously determined factors of workrelated stress. Prior to the COVID-19 pandemic, a high prevalence of burnout in pediatric radiology had been documented [5], with contributing stressors including high call demands, work-life imbalance and a decreased rate of reimbursement [6]. Additional factors associated with high burnout rates included increasing clinical demands and various institutional/ departmental factors, such as covering multiple hospitals and increasing administrative tasks, which ultimately led to decreased job satisfaction as well as significant mental health ramifications [7].

An initial study among internal medicine physicians during the beginning of the pandemic investigated potential stressors and anxieties caused by the circumstances related to COVID19 [8]. The findings showed participants were concerned about (1) uncertainty related to the continuously evolving situation, (2) maintaining protection from the virus while effectively providing patient care and (3) adequate support to handle non-work-related stressors [8]. These challenges can affect physicians of all specialties; however, subspecialty-specific issues need to be considered as well. In radiology, work-life integration was impacted, with many radiologists working from home while managing new-onset home stresses such as caring for children, managing distance learning for children and keeping high-risk populations, such as elders and those with underlying medical conditions, safe [9]. Clinical demands varied significantly given overall lower examination volumes during the time of mandated social distancing while new challenges, such as virtual teaching and consultations, arose. Creating and implementing appropriate PPE guidelines when dealing with potentially infected patients or family members, as well as assuring adequate and available PPE for the radiologists and staff, was a challenge faced by many radiology departments [4]. This is especially important for pediatric radiologists given their direct patient interactions in fluoroscopy, US and interventional radiology. In addition, recent medical literature has suggested the stress burden for women physicians has been higher than for men during the COVID-19 pandemic [10]. The purpose of this study was to evaluate potential stress and anxiety among pediatric radiologists associated with the newfound challenges that arose during the early phase of the COVID-19 pandemic, as well as to specifically evaluate the stress burden among female pediatric radiologists during this time.

\section{Materials and methods}

\section{Sample}

This study surveyed members of the Society for Pediatric Radiology (SPR) who are attending physicians in North America. The cohort of physicians included in this survey were the participants of prior surveys regarding burnout in pediatric radiology, and the stressors and drivers of burnout in pediatric radiology [5-7]. Our survey was administered to a sampling frame of 1,206 physician members, with a response rate of 251 responses (21\%) (231 complete, 20 partial). The survey was open from April 27, 2020, to May 22, 2020, with an initial email and one follow-up reminder email. Responses were anonymous and obtained using an online survey tool (SurveyMonkey, San Mateo, CA). This study was exempt from institutional review board approval.

\section{Survey design}

This 31-question survey was designed based on concepts presented in prior papers alluding to potential challenges from the COVID-19 pandemic [8]. Aside from demographic information, the survey had questions regarding working remotely, PPE, redeployment, personal wellness, departmental wellness resources and financial concerns. Most questions were created on a 5-point or 3-point Likert scale (strongly disagree to strongly agree; less, same, more) or magnitude scale (never to frequently). Questions were reviewed by a psychometrician (G.B., with 9 years of experience) to ensure questions would have minimal risk of misinterpretation. The survey questions discussed in this manuscript are included in the Online Supplementary Material. 


\section{Statistical methods}

All analyses were conducted using SAS Software 9.4 (SAS Inc., Cary, NC). Questions were examined both as frequencies with the FREQ procedure and using generalized linear modeling assuming a binomial distribution with the GLIMMIX procedure; some questions were modeled by years in practice or by reported gender, as has been done in prior publications. Statistical significance was established a priori at the 0.05 level, and all interval estimates were calculated for 95\% confidence intervals. All analyses were conducted by G.B.

\section{Results}

\section{Demographics}

The median age of the respondents was 48 years (range 3370 years) and the median number of years in practice was 14 (range 1-45 years). The median pediatric radiology departmental full-time equivalent (FTE) total was 7.4 (range 146). Fifty-three percent of respondents (134/251) were women and $47 \%(117 / 251)$ were men. Fifty-one percent (127/251) of respondents worked in a free-standing children's hospital and $33 \%(84 / 251)$ worked in a children's hospital/division/department as part of a larger institution. Not all 251 respondents answered all the questions (either due to being exempt from certain questions based on logic or due to partial survey completion); therefore, the denominators for the results vary. The reported results were calculated based on the number of respondents who answered a specific question.

\section{Working remotely}

Prior to the onset of the COVID-19 pandemic, 71\% (124/175) of respondents reported having the ability to read imaging examinations remotely from home. During the onset of mandated social distancing, this increased to $81 \%(202 / 251)$. Of those who had the ability to read remotely prior to the pandemic, 94\% (163/173) endorsed increased utilization of remote reading capabilities at home. Ninety-three percent of respondents (161/174) reported performing more academic and administrative tasks, in addition to clinical tasks, remotely.

As seen in Fig. 1, for those working remotely from home, the majority were able to communicate easily with referring physicians and radiology staff at the hospital ( $81 \%$ strongly agreed/agreed). Over half believed their patient care contribution remained effective while working remotely (67\% strongly agreed/agreed). However, $69 \%(17 / 170)$ reported feeling more isolated because of lack of regular interactions with colleagues because of the mandated social distancing. Fifty-three percent of the

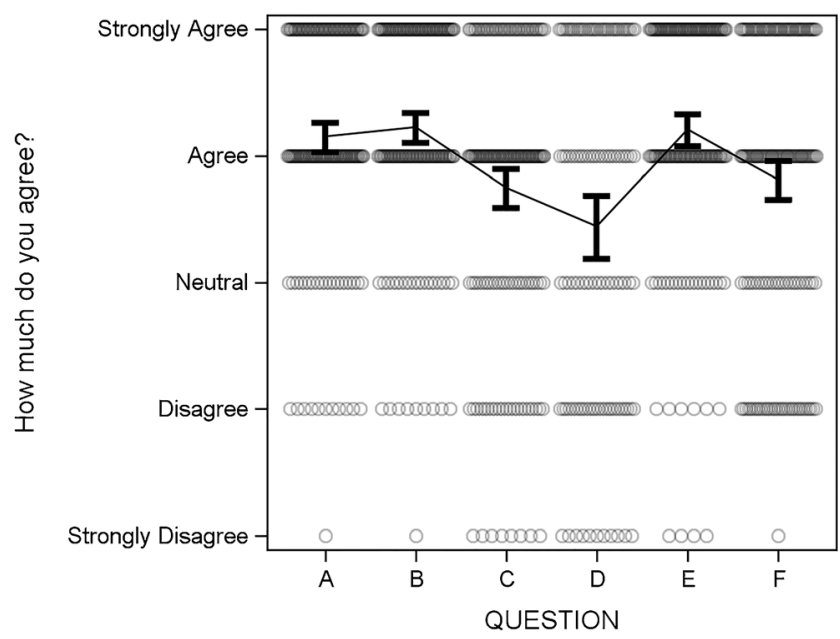

Fig. 1 Perceptions of challenges associated with remote working. The question asked the respondents, "Since starting working remotely at home because of social distancing, please rate how much you agree with the following statements:" A. I am able to communicate easily with clinicians at the hospital regarding clinical work. B. I am able to communicate easily with technologists/nurses/radiology department staff at the hospital while working remotely at home. C. Compared to the time prior to increased social distancing, I now feel more isolated because of lack of interaction with colleagues regularly. D. It has been a challenge to balance working remotely from home with overseeing home schooling for children. E. I have adequate support from my department leadership while dealing with the newfound challenges of working from home. F. My contribution to patient care is as effective while working remotely from home compared to working at the hospital

respondents agreed or strongly agreed that it is challenging to work remotely from home while overseeing home schooling for children.

Eighty-three percent of respondents (139/168) agreed or strongly agreed with having adequate support from departmental leadership while dealing with newfound challenges in the early phase of the COVID-19 pandemic. The majority of respondents found that informational technology (IT) support was adequate and accessible for reading cases remotely (83\%; 142/170 strongly agreed/agreed) and for virtual communication with hospital staff (69\%; 117/170 strongly agreed/ agreed).

\section{Personal protective equipment}

A majority of respondents endorsed having adequate PPE available relative to individual daily risk $(91 \% ; 218 / 240)$ and appropriate direction from the institution/department on PPE use $(86 \% ; 204 / 236)$. Seventy-four percent (172/ 233) agreed or strongly agreed with having adequate guidance on appropriate departmental protocols in order to feel protected when interacting with patients under investigation (PUI) for SARS CoV-2 or COVID-19-positive patients. 


\section{Redeployment}

Twenty-seven percent (63/237) of respondents were asked to consider redeployment, with only 3\% (2/63) redeployed. When respondents were asked whether they would consider redeployment, 41\% (71/172) said yes and 39\% (67/172) said it depended on whether the tasks were within their competency and comfort levels.

\section{Personal wellness}

Many respondents endorsed having increased work-related stress because of mandatory changes associated with the early phase of the COVID-19 pandemic $(58 \% ; 135 / 234)$ as well as feeling more guilt because of radiology staff (i.e. technologists, nurses, etc.) having increased exposure and being at higher risk of contracting the virus compared to the respondents $(69 \%$; 159/232). The majority endorsed decreased job enjoyment because of a lack of social interaction with colleagues in the department $(64 \% ; 147 / 231)$ and a lack of regular patient interaction $(56 \% ; 128 / 228)$ during the social distancing guidelines.

During social distancing, 41\% (94/228) agreed or strongly agreed that balancing demands of work with time for personal and family life was a major source of stress, while 38\% (74/ 197) agreed or strongly agreed that stress was in part from providing, organizing and paying for dependent care.

Women reported higher work-related stress and anxiety than men $(P=0.02)$ and greater feelings of guilt than men over radiology staff being more exposed to and at higher risk for contracting COVID-19 $(P=0.02)$. In addition, women reported slightly higher levels of stress in providing, organizing or paying for dependents than men $(P=0.04)$ (Table 1). There was no difference between genders regarding challenges associated with working remotely and overseeing home schooling.

As the number of years in practice increased, the odds of work-related stress and anxiety decreased by $2 \%$ (odds ratio [OR]: $1.02 ; 95 \%$ confidence interval [CI]: 0.003, 3.03; $P=0.02$ ) for every year (Fig. 2). Similarly, for every additional year in practice, the odds of less work-related enjoyment because of lack of regular social interactions with colleagues increased 2\% (OR: 1.02; 95\% CI: 0.003, 3.03; $P=0.02$ ) (Fig. 3).

\section{Wellness resources}

A majority of respondents thought departmental leadership was effective in providing regular communication to the staff regarding updates during the early phase of the COVID-19 pandemic $(78 \% ; 180 / 230)$ and indicated they felt comfortable contacting departmental leadership with concerns, questions and anxieties (79\%; 181/230). Fifty-two percent (120/230) frequently or always thought their department provided adequate access to wellness resources. As seen in Table 2, we found no statistically significant differences between men and women on perceptions regarding available wellness resources.

\section{Financial concerns}

While most respondents were rarely or never concerned about having difficulties meeting financial obligations $(81 \% ; 187 /$ $230)$ or losing their job $(74 \% ; 170 / 230), 34 \%$ (78/229) had little or no fear of taking a substantial reduction in pay and $43 \%$ (99/230) had little or no concern about their current financial situation. As seen in Table 3, there was no statistically significant difference between women and men with regard to financial concerns.

\section{Discussion}

The majority of respondents in our study endorsed having increased work-related stress because of mandatory changes implemented during the COVID-19 pandemic. Many potential factors contribute to this; however, our survey results highlight some key findings favorable toward creating potential interventions to alleviate stress and anxiety associated with this pandemic as well as for future practice (Table 4).

The most striking result is the gender difference in the perceived stress and anxiety related to the mandatory changes in the early phase of the COVID-19 pandemic. Specifically, women had statistically significant higher overall stress and anxiety, as well as stress related to providing, organizing and paying for dependent care, than men. It has been well established that women are the majority of primary caregivers, provide more childcare and spend more time on parenting and domestic tasks than their male counterparts [11]. Therefore, stress and anxiety related to juggling work and home life is exacerbated for female radiologists when faced with working from home and needing to supervise home schooling and provide childcare. Our results showed that during the early phase of the pandemic, when schools abruptly went to distance learning, greater than $50 \%$ of respondents encountered stress from managing work-related duties and overseeing home schooling. A survey of one large academic radiology department during the early phase of the COVID-19 pandemic highlighted childcare as a serious concern for radiologists. The results of this survey led to a call for departmental and institutional support to ensure appropriate childcare and to acknowledge the stress associated with working while managing these challenges [9]. Recent articles have also highlighted the disparity in the effect on clinical and academic productivity between women and men from the greater non-workrelated obligations faced by women [10]. This is especially 
Table 1 Differences between gender and personal wellness perceptions $^{\mathrm{a}}$

\begin{tabular}{|c|c|c|c|c|c|c|c|}
\hline \multirow[b]{3}{*}{$\begin{array}{l}\text { My work-related stress/anxiety has increased because of } \\
\text { mandatory changes implemented due to COVID-19 } \\
\text { pandemic. }\end{array}$} & \multicolumn{3}{|c|}{ Women } & \multicolumn{3}{|l|}{ Men } & \multirow{3}{*}{$\begin{array}{l}P \text { - } \\
\text { value }^{\mathrm{b}}\end{array}$} \\
\hline & \multirow{2}{*}{ Mean } & \multicolumn{2}{|c|}{$95 \% \mathrm{CI}$} & \multirow{2}{*}{ Mean } & \multicolumn{2}{|c|}{$95 \% \mathrm{CI}$} & \\
\hline & & 2.4 & 2.8 & & 2.0 & 2.5 & \\
\hline $\begin{array}{l}\text { I feel guilty because technologists, nurses and other staff } \\
\text { in my department are at higher risk due to being } \\
\text { exposed to the virus more frequently, while I am } \\
\text { relatively protected. }\end{array}$ & 2.9 & 2.7 & 3.1 & 2.6 & 2.3 & 2.8 & 0.017 \\
\hline $\begin{array}{l}\text { The lack of regular social interactions with colleagues in } \\
\text { the department due to mandated social distancing } \\
\text { guidelines has made doing my job less enjoyable. }\end{array}$ & 2.6 & 2.4 & 2.8 & 2.8 & 2.5 & 3.0 & 0.13 \\
\hline $\begin{array}{l}\text { Working with mandated social distancing guidelines } \\
\text { has heightened how regular patient interaction while } \\
\text { working physically in the department is important for } \\
\text { enjoying my job. }\end{array}$ & 2.5 & 2.3 & 2.7 & 2.6 & 2.4 & 2.8 & 0.25 \\
\hline $\begin{array}{l}\text { I have relatively less stress/anxiety while working } \\
\text { remotely due to lower personal risk (feel more } \\
\text { protected). }\end{array}$ & 2.7 & 2.4 & 2.9 & 2.5 & 2.3 & 2.7 & 0.13 \\
\hline $\begin{array}{l}\text { I have regular virtual communication (outside of } \\
\text { work-related activities) with my pediatric radiology } \\
\text { colleagues in my department since mandated social } \\
\text { distancing guidelines were implemented. }\end{array}$ & 2.5 & 2.2 & 2.7 & 2.3 & 2.1 & 2.5 & 0.13 \\
\hline $\begin{array}{l}\text { Trying to balance the demands of my work with the } \\
\text { time needed for my personal and family life is a major } \\
\text { source of stress in my life currently. }\end{array}$ & 2.1 & 1.9 & 2.3 & 2.1 & 1.9 & 2.3 & 0.49 \\
\hline $\begin{array}{l}\text { Providing, organizing, or paying for care for dependents } \\
\text { (e.g., children, elderly family members) is a major } \\
\text { source of stress in my life currently. }\end{array}$ & 2.0 & 1.7 & 2.3 & 1.6 & 1.4 & 1.9 & 0.038 \\
\hline
\end{tabular}

CI confidence interval, COVID-19 coronavirus disease 2019

a The question asked respondents, "How much do you agree with the following statements?" (strongly disagree, 0 , to strongly agree, 4)

${ }^{\mathrm{b}} P<0.05$ is significant (bold)

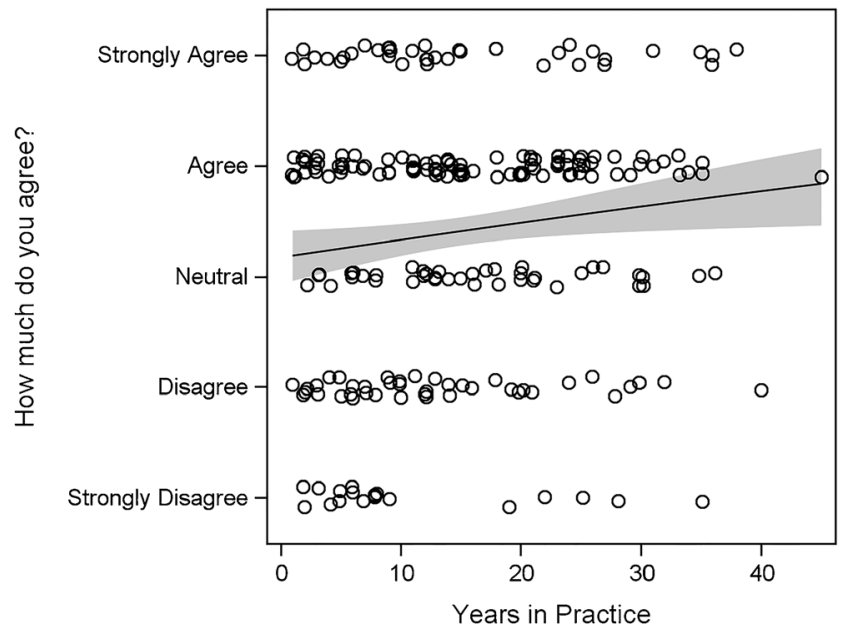

Fig. 2 Work-related stress/anxiety during the early phases of the COVID19 pandemic by years in practice. Respondents were asked how much they agreed with the following statement: "My work-related stress/ anxiety has increased because of mandatory changes implemented due to COVID-19 pandemic." The line is the slope between years of practice and level of agreement. The shaded area is the 95\% confidence band around the slope

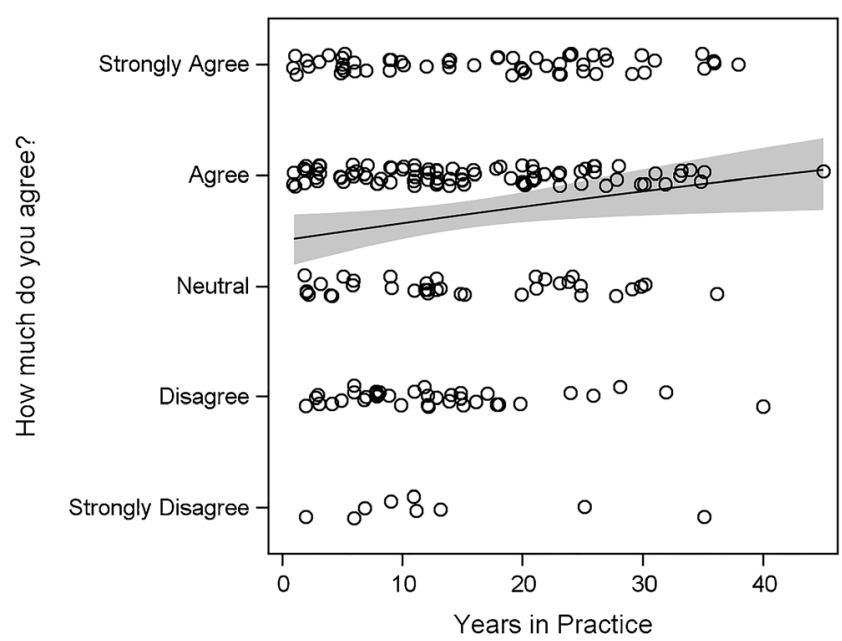

Fig. 3 Perceptions of importance of social interactions by years in practice. Respondents were asked how much they agreed with the following statement: "The lack of regular social interactions with colleagues in the department due to mandated social distancing guidelines has made doing my job less enjoyable." The line is the slope between years of practice and level of agreement. The shaded area is the $95 \%$ confidence band around the slope 
Table 2 Differences between gender and perceptions of departmental wellness initiatives $^{\mathrm{a}}$

\begin{tabular}{|c|c|c|c|c|c|c|c|}
\hline \multirow[b]{3}{*}{$\begin{array}{l}\text { My department has provided adequate access to } \\
\text { wellness resources for the department members. }\end{array}$} & \multicolumn{3}{|c|}{ Women } & \multicolumn{3}{|l|}{ Men } & \multirow{3}{*}{$\begin{array}{l}P- \\
\text { value }^{\mathrm{b}}\end{array}$} \\
\hline & \multirow{2}{*}{$\frac{\text { Mean }}{2.6}$} & \multicolumn{2}{|c|}{$95 \% \mathrm{CI}$} & \multirow{2}{*}{ Mean } & \multicolumn{2}{|c|}{$95 \% \mathrm{CI}$} & \\
\hline & & 2.4 & 2.8 & & 2.2 & 2.7 & \\
\hline $\begin{array}{l}\text { The leadership in my department has been effective in } \\
\text { providing regular communication to the staff } \\
\text { regarding updates since the onset of the COVID-19 } \\
\text { pandemic. }\end{array}$ & 3.2 & 3.0 & 3.4 & 3.3 & 3.1 & 3.4 & 0.40 \\
\hline $\begin{array}{l}\text { I can comfortably contact leaders and supervisors in my } \\
\text { department with concerns, questions and anxieties. }\end{array}$ & 3.2 & 3.0 & 3.3 & 3.3 & 3.1 & 3.5 & 0.095 \\
\hline
\end{tabular}

CI confidence interval, COVID-19 coronavirus disease 2019

${ }^{\text {a }}$ The question asked respondents, "How often do the following statements refer to how you feel since the imposed new challenges related to COVID-19 pandemic?" (never, 0, to always, 4)

${ }^{\mathrm{b}} P<0.05$ is significant

important in that female radiologists, as primary caregivers, might be less productive because of these added duties, which sets women up for more difficult academic advancement and even leads to more women choosing to leave their radiology career [12].

During the time of mandated social distancing, many departments increased capabilities for radiologists to work remotely from home, which allowed for flexibility to accommodate for the abrupt new challenges of lack of childcare and the supervision of distance learning [3, 13]. Prior to the pandemic, lack of control of one's work schedule was a potential driver of burnout in radiology [14], with flexible work schedules and work environments as a potential solution to mitigate burnout and promote physician wellness. The early phase of the pandemic has shown it will be important to try to regularly incorporate remote working capabilities as part of the standard radiologist work schedule. The respondents of this survey viewed remote work positively, with the majority endorsing adequate IT support and the ability to easily communicate with referring physicians and other radiology staff while working from home. Despite the availability of vaccines, social distancing to help curb the continuing spread of the virus is likely to be needed for some time. Flexibility in scheduling and recognition of support needed to balance non-workrelated stresses were issues prior to the COVID-19 pandemic. The additional stresses created in the early phase of the pandemic have emphasized the need to more urgently address these issues. It is more important than ever for pediatric radiology departments to incorporate regular remote reading capabilities and flexibility with work schedules for departmental staff to feel supported while continuing to manage workrelated duties and their many non-work-related challenges.

One disadvantage of remote work is the increased isolation. Sixty-nine percent of the respondents agreed or strongly agreed that they felt more isolated while working at home. Pediatric radiology is a unique specialty allowing for more patient interaction than many other radiology subspecialties, especially with regard to US, fluoroscopy and interventional radiology procedures. Interactions with parents and other caregivers can be one of the most highly rewarding aspects of the job; however, COVID-19 made these interactions more challenging. Aside from our many interactions with
Table 3 Differences between genders on financial concerns ${ }^{\mathrm{a}}$

\begin{tabular}{|c|c|c|c|c|c|c|c|}
\hline \multirow[b]{3}{*}{ I have concerns about my current financial situation. } & \multicolumn{3}{|c|}{ Women } & \multicolumn{3}{|l|}{ Men } & \multirow{3}{*}{$\begin{array}{l}\begin{array}{l}P- \\
\text { value }\end{array} \\
0.43\end{array}$} \\
\hline & \multirow{2}{*}{$\frac{\text { Mean }}{1.6}$} & \multicolumn{2}{|c|}{$95 \% \mathrm{CI}$} & \multirow{2}{*}{$\frac{\text { Mean }}{1.6}$} & \multicolumn{2}{|c|}{$95 \% \mathrm{CI}$} & \\
\hline & & 1.4 & 1.8 & & 1.3 & 1.8 & \\
\hline $\begin{array}{l}\text { I may have difficulties meeting my financial } \\
\text { obligations. }\end{array}$ & 0.7 & 0.5 & 0.8 & 0.7 & 0.5 & 0.9 & 0.45 \\
\hline I fear taking a substantial reduction in pay. & 1.9 & 1.7 & 2.1 & 1.8 & 1.6 & 2.1 & 0.41 \\
\hline I fear losing my job. & 0.9 & 0.7 & 1.1 & 0.8 & 0.6 & 1.0 & 0.15 \\
\hline
\end{tabular}

CI confidence interval, COVID-19 coronavirus disease 2019

${ }^{\text {a }}$ The question asked respondents, "How often do the following statements refer to you since the onset of the COVID-19 pandemic and mandated social distancing was implemented?" (never, 0, to always, 4)

${ }^{\mathrm{b}} P<0.05$ is significant 
Table 4 Overview of potential sources of stress and anxiety during the early phase of the coronavirus disease 2019 (COVID-19) pandemic and potential areas of focus for interventions

\begin{tabular}{ll}
\hline Sources of stress/anxiety & Areas of focus for interventions \\
\hline Work-life integration & - Flexible work schedules to support work-life integration \\
& - Recognition of and support for childcare needs \\
& - Support for academic endeavors while managing non-work-related stresses \\
Protection from & - Ensure appropriate PPE supplies and access \\
contracting virus & - Create and distribute PPE use protocols in the departments \\
& - Ensure appropriate social distancing guidelines and capabilities in the department \\
(i.e. social distancing in the reading room, remote reading sites, etc.) \\
$\begin{array}{c}\text { Department leadership } \\
\text { support }\end{array}$ & - Regular communication with the faculty/staff \\
\hline
\end{tabular}

$P P E$ personal protective equipment colleagues, these unique aspects of pediatric radiology very much contribute to the joy felt by pediatric radiologists $[15$, 16], much of which has been lost with mandated social distancing. Prior to the pandemic, isolation had been established as a potential driving factor for burnout in radiology. As efforts are made to mitigate burnout and the new-found stresses associated with the COVID-19 pandemic, we must acknowledge that there might be a greater risk of isolation than before. Given that the effects of the pandemic are likely to continue for some time, departments need to consider measures to provide support to staff and ensure a sense of community and collegiality in new and innovative ways. Potential solutions include engaging staff in virtual social gatherings and having a rotating schedule for those who can work safely in-person in the department.

A majority of the respondents confirmed having adequate protection from contracting the virus. Most respondents in our study endorsed having adequate available PPE for personal daily risk mitigation. Pediatric radiology involves unique instances involving aerosolization, such as air reduction enemas for intussusception, as well as small crying children who are too young to wear a mask to prevent droplet spread. Multiple institutional experiences have been collated to help provide guidance for appropriate PPE use for different scenarios and procedures in pediatric radiology [17]. Moving forward, it is important to continue to ensure the availability of PPE, especially N95 masks or equivalent respirators, to protect radiologists and other staff from contracting the virus or spreading it in high-risk situations. This is especially important for those more vulnerable to contracting the virus, such as older staff and those with underlying medical conditions that might predispose them to worse outcomes if they do become ill with the SARS-CoV-2 virus.

A majority of the survey respondents endorsed that departmental leadership provided frequent communication and updates during the pandemic, and felt comfortable contacting department leadership regarding related concerns, questions or anxieties. Prior to the pandemic, one important driver associated with burnout was lack of effective leadership, communication and transparency [18]. The unprecedented events of the COVID-19 pandemic have left departments with new challenges and questions to tackle together. The loss of control and sense of safety has highlighted the critical need for effective and present leadership to help radiologists and other staff process and handle these challenges. It is important to continue open communication with opportunities for faculty and staff input and feedback [19].

The results of our survey showed that respondents overall did not have concerns regarding meeting financial obligations or losing their job. However, respondents were concerned about a substantial pay reduction. It is important to note that the perceptions reflected in this survey are those during the early phase of the COVID-19 pandemic. Since the time of the survey, studies have reported up to $70 \%$ decreases in imaging volumes in radiology practices during mandated social distancing $[20,21]$. One of the greatest contributors was the significant drop in outpatient (non-emergent and elective) imaging examinations, and the resulting financial loss was felt predominantly by outpatient imaging practices [21]. Pediatric radiologists are predominantly based at academic institutions with a combination of inpatient/emergency and outpatient imaging; therefore, the cohort responding to our survey might work at institutions with less financial concern than primarily outpatient imaging practices. The financial implications from the COVID-19 pandemic are still being examined. Given continuing uncertainty, precautions might be instituted to prepare for future losses, such as staff reductions, salary cuts, lack of bonuses, or restricted contributions to retirement savings. Further information needs to be obtained to see the overall financial implications to pediatric radiology.

The major limitation of this study is the response rate $(21 \%$; $251 / 1,206$; 20 of the responses were partial), with the viewpoints of this survey representing those of the participants. The response rate of this survey is similar to that of other surveys performed by the Society for Pediatric Radiology on burnout $[5,7]$ as well as similar surveys performed in other 
radiology specialties [22]. One difference from prior studies is the climate in which this survey was performed - the early phase of the COVID-19 pandemic, which was a stressor in itself [23]. Every individual and department is facing different challenges and experiencing different levels of stress and anxiety associated with these challenges. The cohort of people who participated in this survey might have been experiencing stress and anxiety associated with the COVID-19 pandemic at a different level or for different reasons than non-responders; however, it is important to evaluate this information as part of ongoing initiatives to mitigate burnout and promote wellness in pediatric radiology. Additional limitations include the lack of information obtained about impact on education, as well as the mitigation methods for stress and anxiety attempted by the respondents. The length of the survey needed to be limited to prevent survey fatigue; therefore, future studies would be beneficial.

\section{Conclusion}

This survey sheds light on the additional stress and anxiety felt by the responding pediatric radiology faculty during the early phase of the COVID-19 pandemic, especially the critical finding of the higher stress burden felt by female pediatric radiologists during this time. Given the continuously evolving state of the COVID-19 pandemic, it is important to use these results as a springboard for further planning and implementation of strategies to combat potential increases in burnout among pediatric radiologists.

Supplementary Information The online version contains supplementary material available at https://doi.org/10.1007/s00247-021-05088-7.

\section{Declarations}

Conflicts of interest None

\section{References}

1. Bedford J, Enria D, Giesecke J et al (2020) COVID-19: towards controlling of a pandemic. Lancet 395:1015-1018

2. Mossa-Basha M, Meltzer CC, Kim DC et al (2020) Radiology department preparedness for COVID-19: Radiology scientific expert review panel. Radiology 296:E106-E112

3. Ertl-Wagner BB, Lee W, Manson DE et al (2020) Preparedness for the COVID-19 pandemic in a tertiary pediatric radiology department. Pediatr Radiol 50:1059-1068

4. Phillips CD, Shatzkes D, Moonis G et al (2020) From the eye of the storm: multi-institutional practical perspectives on neuroradiology from the Covid-19 outbreak in New York City. AJNR Am J Neuroradiol 41:960-965

5. Ayyala RS, Ahmed FS, Ruzal-Shapiro C, Taylor GA (2018) Prevalence of burnout among pediatric radiologists. J Am Coll Radiol 16:518-522
6. Ayyala RS, Ahmed F, Ruzal-Shapiro CB, Taylor G (2019) Stressors contributing to burnout amongst pediatric radiologists: results from a survey of the Society for Pediatric Radiology. Pediatr Radiol 49:714-722

7. Ayyala RS, Baird GL, Sze R et al (2020) The growing issue of burnout in radiology - a survey-based evaluation of driving factors and potential impacts in pediatric radiologists. Pediatr Radiol 50:1071-1077

8. Shanafelt T, Ripp J, Trockel M (2020) Understanding and addressing sources of anxiety among health care professionals during the COVID-19 pandemic. JAMA 323:2133-2134

9. Joshi A, Garver KA, Balasubramanian S et al (2020) Childcare for radiology workers during the COVID-19 pandemic: no small matter. J Am Coll Radiol 17:1532-1534

10. Madsen TE, Dobiesz V, Das D et al (2020) Unique risks and solutions for equitable advancement during the Covid-19 pandemic: early experience from frontline physicians in academic medicine. NEJM Catal Innov Care Deliv. https://catalyst.nejm.org/doi/full/10. 1056/cat.20.0268. Accessed 7 Apr 2021

11. Jolly S, Griffith KA, DeCastro R et al (2014) Gender differences in time spent on parenting and domestic responsibilities by highachieving young physician-researchers. Ann Intern Med 160: 344-353

12. Esfahani SA, Lee A, Hu J-Y et al (2020) Challenges faced by women in radiology during the pandemic - a summary of the AAWR Women's caucus at the ACR 2020 annual meeting. Clin Imaging 68:291-294

13. Sammer MBK, Sher AC, Huisman TAGM, Seghers VJ (2020) Response to the COVID-19 pandemic: practical guide to rapidly deploying home workstations to guarantee radiology services during quarantine, social distancing, and stay home orders. AJR Am J Roentgenol 215:1417-1420

14. Harolds JA, Parikh JR, Bluth EI et al (2016) Burnout of radiologists: frequency, risk factors, and remedies: a report of the ACR Commission on human resources. J Am Coll Radiol 13:411-416

15. Strouse PJ, Romberg EK, Jarrett DY et al (2020) The continuous lure of pediatric radiology. Pediatr Radiol 50:3-12

16. Gunderman RB (2001) The lure of pediatric radiology. AJR Am J Roentgenol 176:1371-1373

17. Miranda-Schaeubinger M, Blumfield E, Chavhan GB et al (2020) A primer for pediatric radiologists on infection control in an era of COVID-19. Pediatr Radiol 50:1191-1204

18. Fishman MDC, Mehta TS, Siewert B et al (2018) The road to wellness: engagement strategies to help radiologists achieve joy at work. Radiographics 38:1651-1664

19. Ayyala RS, Taylor GA, Callahan MJ (2020) Stresses and anxieties in the time of the COVID-19 pandemic — what we can learn. Pediatr Radiol 50:1052-1054

20. Mossa-Basha M, Deese J, Vincic D, Sahani DV (2020) Coronavirus disease 2019 (COVID-19): radiology department financial impact and planning for post-COVID recovery. J Am Coll Radiol 17:894898

21. Cavallo JJ, Forman HP (2020) The economic impact of the COVID-19 pandemic on radiology practices. Radiology 296: E141-E144

22. Ganeshan D, Rosenkrantz AB, Bassett RL et al (2020) Burnout in academic radiologists in the United States. Acad Radiol 27:1274 1281

23. Restauri N, Sheridanmd AD (2020) Burnout and posttraumatic stress disorder in the coronavirus disease 2019 (COVID-19) pandemic: intersection, impact, and interventions. J Am Coll Radiol 17:921-926

Publisher's note Springer Nature remains neutral with regard to jurisdictional claims in published maps and institutional affiliations. 